\title{
Atlantic and Pacific Multidecadal Variability Influence on Taiwan Winter Temperature Centennial Trend During the Period 1911 - 2010
}

\author{
Mong-Ming $\mathrm{Lu}^{1, *}$, Yin-Min $\mathrm{Cho}^{1}$, Yun-Ching $\operatorname{Lin}^{1}$, and Norden E. Huang ${ }^{2}$ \\ ${ }^{1}$ Central Weather Bureau, Taipei City, Taiwan, R.O.C. \\ ${ }^{2}$ Research Center for Adaptive Data Analysis, National Central University, Taoyuan City, Taiwan, R.O.C.
}

Received 20 May 2015, revised 13 June 2016, accepted 30 June 2016

\begin{abstract}
The sea surface temperature (SST) of the marginal seas off the East coast of China is known for its large warming trend during the twentieth century. The station data in Taiwan is of particular importance as a reliable complementing measurement for SST. This paper analyzes the temperature from 1911 - 2010 at six stations using the data adaptive method Ensemble Empirical Mode Decomposition (EEMD). Multidecadal modes (period > 40 years) in winter with the warm (1931 - 1950) and cold (1971 - 1980) phases are identified. In addition to the warm and cold phases, the $1951-1970$ period is identified as the cooling phase, a transition phase from a warm to a cold regime, while the 1911 - 1930 and 1991 - 2010 periods are identified as the warming phase. The multidecadal variability in the Taiwan winter temperature is robust because it is rooted in the major multidecadal variability modes of the global SST, the Atlantic multidecadal oscillation (AMO), and the Pacific Decadal Oscillation (PDO). The centennial secular trend (ST) shows much larger warming rate than the linearly regressed. Because the multidecadal mode has been in a warming phase since 1991, the surpassed warming rate is likely due to a compensation effect to the decadal or sub-decadal scale cooling variations, while the possibility of anthropogenic influence cannot be ruled out.
\end{abstract}

Key words: Taiwan temperature, Multidecadal climate variability, AMO, PDO

Citation: Lu, M. M., Y. M. Cho, Y. C. Lin, and N. E. Huang, 2016: Atlantic and Pacific multidecadal variability influence on Taiwan winter temperature centennial trend during the period 1911 - 2010. Terr. Atmos. Ocean. Sci., 27, 605-615, doi: 10.3319/TAO.2016.06.30.02

\section{INTRODUCTION}

The most convincing evidence of changing climate represented by instrumental measurements is the global warming of the surface air and ocean temperatures. The atmospheric and ocean surface temperatures do not show a monotonic increasing trend similar to what is found for the greenhouse gas concentrations. The global mean temperatures during the $20^{\text {th }}$ century show clear warming and cooling fluctuations in the decadal time scale (Semenov et al. 2010; DelSole et al. 2011; Wu et al. 2011). The multidecadal variability of global sea surface temperature (SST) is an area of vigorous study. Modes with such low-frequency variations include the Atlantic multidecadal oscillation (AMO), the Pacific decadal oscillation (PDO), the Inter-decadal Pacific Oscillation (IPO), and the North Pacific Gyre Oscillation (NPGO). The PDO spatial pattern is similar to the El Niño-Southern Oscillation (ENSO) but the former has more

\footnotetext{
* Corresponding author

E-mail:lu@rdc.cwb.gov.tw
}

weight on the extra-tropics while the latter has more weight on the tropics. A thorough review of these modes is given in Deser et al. (2010a).

The secular trend (ST) of the $20^{\text {th }}$ century global and regional SST can be derived after filtering out the low-frequency noise (Guan and Nigam 2008, 2009; Deser et al. 2010a, b; Solomon and Newman 2012). It is commonly found that the largest ST of warming appears off the East coasts of China and northern North America. A drawback to climate change studies is the lack of sufficiently long observational data. Since Taiwan temperature is highly correlated with the SST over the East China Sea, the temperature data observed at the meteorological stations in Taiwan are of extreme importance as a complementary measurement to SST.

The objective of this paper is to identify the multidecadal modes and ST of Taiwan temperature using the data from 1911 - 2010. Because the conventional linear trend analysis cannot discern different time scales at slow variations, more sophisticated methods are needed. We found 
that the Ensemble Empirical Mode Decomposition (EEMD) (Wu and Huang 2009) proposed by Wu et al. $(2007,2011)$ is a powerful method for identifying the multidecadal mode and centennial ST. EEMD is an empirical and non-parametric data adaptive algorithm. The multidecadal mode and ST separation is a critical step toward understanding how local climate in the tropical western boundary of the Pacific changes with the major global SST multidecadal variability modes.

\section{DATA AND METHOD}

Taiwan temperature data observed at 6 stations from November 1910 to February 2011 were used. The station names and locations are shown in Fig. 1. These stations are well managed with no missing data during the study analysis period. The NOAA Extended Reconstructed SST version 3 (ERSSTv3b) (Smith et al. 2008) obtained from the http://www.ncdc.noaa.gov/ersst/ website was used for the global SST. We used the data prepared by NOAA National Climatic Data Center available at the http://www.ncdc. noaa.gov/cmb-faq/anomalies.php website for the global and hemispherical mean temperatures.

The EEMD method concept and analysis procedure are documented in $\mathrm{Wu}$ and Huang (2009). The EEMD is a modification of the basic adaptive decomposition method EMD (Huang et al. 1998, 1999). It does not require any predetermined time scale, parameters or functions that are subjective and extrinsic. The trends extracted by EEMD were determined using an iterative intrinsically fitting procedure that allows only one extremum within a given data span. The given data span could be the whole length or a part of the data. The decomposition is based on the time scale separation in physical space. The data is first subject to the local extrema identification. The local maxima (minima) are then connected using a cubic natural spline line to form the upper (lower) envelope. The deviation from the upper and lower envelope mean is used for estimating the shortest time scale component through an iteration procedure until the extracted component satisfies the intrinsic mode function (IMF) definition. The IMF is defined as a function that has the same number of extrema and zero-crossing and that the upper and lower envelope mean is zero. The above procedure could be repeated to the residue repeatedly until the final residue becomes a monotonic function.

\section{RESULTS}

Taiwan is located in the western subtropical boundary region of the Pacific, where the regional climate is strongly (b)

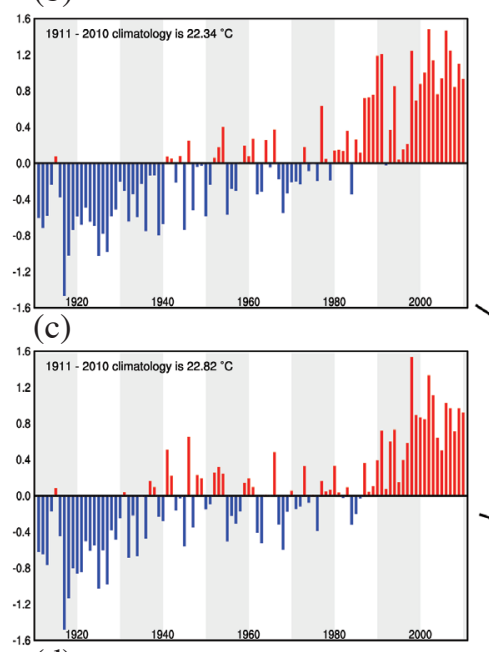

(d)

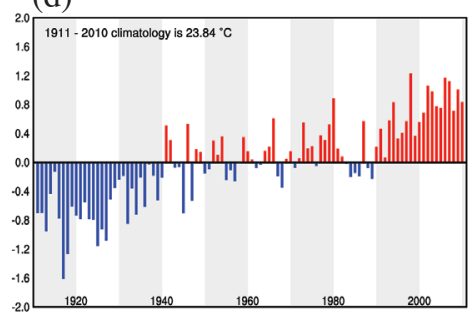

(a)
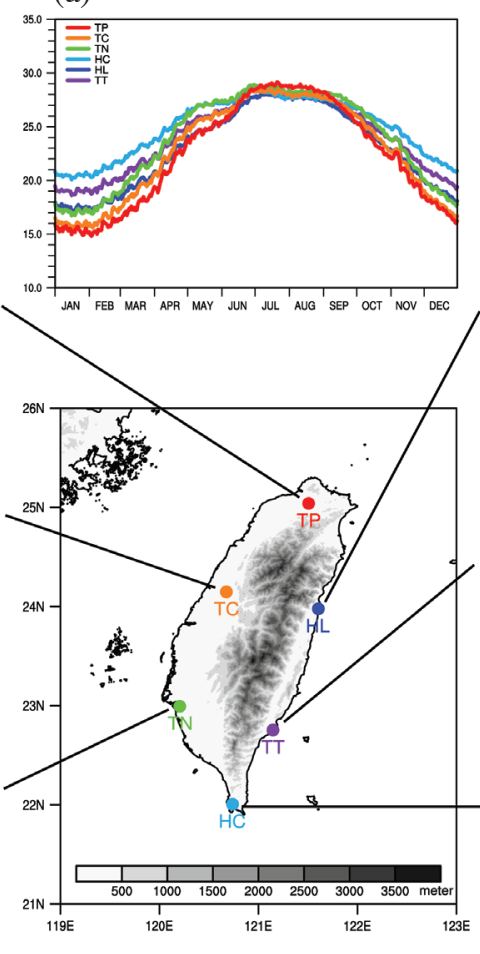

(e)

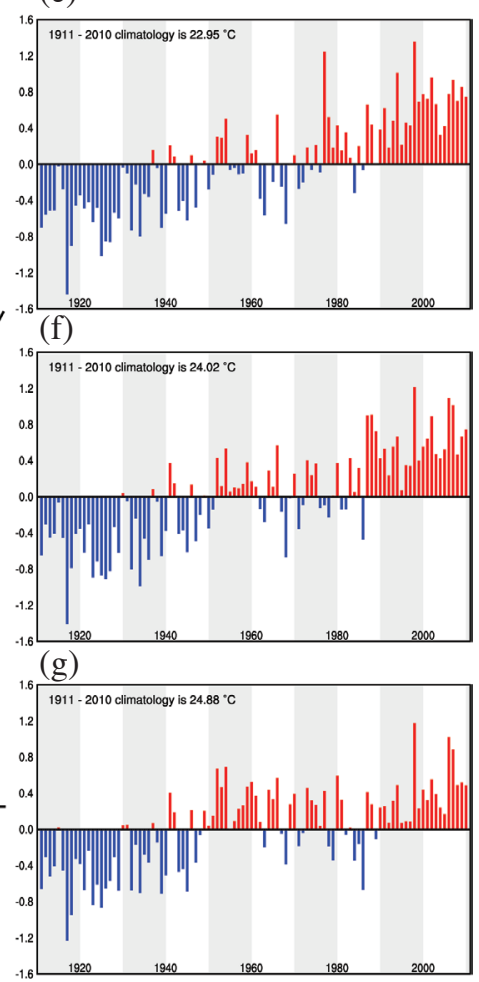

Fig. 1. The daily climatology and the time series of annual mean temperatures anomalies at 6 Taiwan stations based on the data from 1911 - 2010 ; (a) daily climatology, (b) - (g) the time series of the annual mean temperatures anomalies at (b) Taipei, (c) Taichung, (d) Tainan, (e) Hengchun, (f) Taitung, and (g) Hualien. The climatological mean temperature averaged over the period of $1911-2010$ is written on the left top of the diagram of each station. 
modulated by the East Asian winter and summer monsoons. The 100-year daily temperature climatology in Taiwan (Fig. 1a) shows the annual range of the temperatures in general is less than $15^{\circ} \mathrm{C}$. The warmest season is from mid-June to mid-September and the coldest season is from December to February. In this paper, we define season as a period of three successive months. Note that the inter-station difference in the mean temperature is small. It is less than $2^{\circ} \mathrm{C}$ in summer, but slightly larger in winter. The relatively large winter difference is due to the geographic effect of the mountains that block the northeasterly winter monsoon that originates from the Asian continent. The geographic effect is manifested in precipitation rather than temperature during the Asian summer monsoon season.

In the past 100 years, the Taiwan climate can be separated into warm and cold periods. Figure 1 shows that by visual estimation the warm period began in the late 1980s and lasted until 2010. The cold period started in 1911 and ended in the early 1940s. From the early 1940s to late 1980s, the climate fluctuated between moderate warm and cold. At Hengchun, which is located near the southernmost tip of Taiwan Island, the warm years are more distinct than the cold years, while the temperature contrast between the warm and cold periods is largest at Taipei. The annual range of temperature climatology in Taipei is also the largest. The correlation between Taiwan and the global mean temperatures is very high. The 100-year correlation is 0.81 .

It is evident that the warming rate during the past 100 years was not constant. Using the EEMD method, we can identify the centennial ST of warming and the multidecadal variability. Four parameters $(\mathrm{S}, \mathrm{N}, \sigma, \mathrm{I})$ are required in the EEMD analysis (Wu et al. 2011). S defines the numbers of zero-crossing and extrema, it is also known as the number of consecutive siftings. $\mathrm{N}$ defines the ensemble number, $\sigma$ the constraint of the standard deviation of white noise, and I the number of iterations for the ensemble process. More iterations ensure a more stable result. In this study we use the parameters $(\mathrm{S}, \mathrm{N}, \sigma, \mathrm{I})$ of $(10,100,0.1,50)$ to decompose the 100 -year time series into five IMFs and a ST. The ST by definition is a trend that is not cyclical or seasonal but exists over a relatively long period. It is obtained by removing all IMFs from the original time series.

The EEMD analysis is applied to the temperature data at each station and the average of 6 stations. The statistical significance of the IMF is tested using the method proposed by $\mathrm{Wu}$ and Huang (2005). The purpose of the significance test is to determine what IMF can be rejected from pure noise at the $95 \%$ confidence level. An example of the decomposition is presented in Fig. 2. In the Hengchun station example, we found that only the fifth IMF (IMF5) with which the period is about 50 years is statistically significant.

In order to identify the seasonality of the multidecadal modes and ST, the EEMD is applied to the seasonal and annual means at all stations. There are twelve seasons in total and every two subsequent seasons differ by one month. The 6 stations with 12 seasonal and 1 annual mean time series result in 390 IMFs, among them 53 IMFs pass the 95\% level significance test. Thirty-seven (70\%) of the statistically significant IMFs have periods longer than 40 years and $6(11 \%)$ have periods less than 10 years. All significant IMFs with periods between 10 - 40 years appear during the summer seasons from AMJ to SON. The statistically significant multidecadal modes are summarized in Table 1. Because our focus is on the multidecadal modes (period $>40$ years) and ST, only the winter temperature characteristics will be discussed. The other variability is beyond the scope of this paper.

The IMFs in winter seasons (NDJ, DJF, and JFM) show coherent multidecadal variations (Fig. 3a). A warm regime during the 1930s and 1940s decades and a cold regime during the 1970s and 1980s decades can be clearly identified. The past two 1990s and 2000s decades are the transition period from cold to warm. A remarkable cooling tendency is observed at all stations from the early 1950s to mid-1970s. It is of critical importance to understand the cooling trend because it can be a counter effect to the warming in centennial time scale.

The ST of the winter temperatures derived using the EEMD method is in general much larger than the conventional linear-regressed trend. To illustrate this point we present the ST of the NDJ temperature in Fig. 3b against the linear trends at 6 stations. Unlike the constant warming rate estimated using the linear regression method, the slope represented by the EEMD ST can depict important temporal variations in warming. The ST at all 6 stations suggests smaller variations than the linear trend before the mid1970s. After the mid-1970s, the ST shows a larger warming rate than the linear trend. This finding is consistent with the previously published results (Guan and Nigam 2008, 2009; Deser et al. 2010a, b; Solomon and Newman 2012). It was pointed out previously that after removing the inter-annual to multidecadal variations the largest warming trend in twentieth-century SST appeared along the eastern coasts of Asia (e.g., Fig. 1 in Guan and Nigam 2009), including the boundary sea surrounding Taiwan. Recall that ST derived from EEMD method is a monotonic function of the final residue. Therefore, the surpassed warming rate is likely due to a compensation effect to the cooling of decadal or sub-decadal scale variations because the multidecadal mode shows clear warming tendency after 1991, while the possibility of anthropogenic influence cannot be ruled out.

\section{DISCUSSION}

The EEMD analysis result clearly shows that the Taiwan winter temperature has a significant multidecadal mode (IMF5). The strongest signal appears in early winter from November to January. Understanding the robustness of this mode is extremely important for interpreting how Taiwan is 

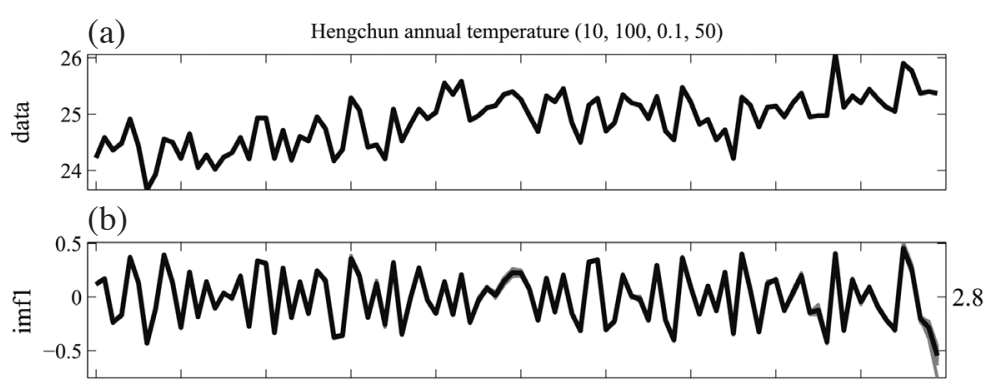

(c)

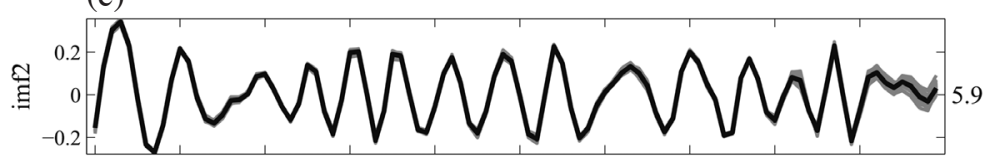

(d)

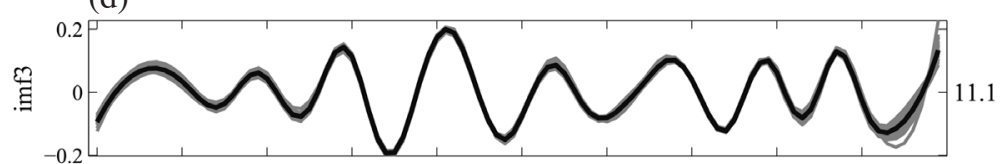

(e)

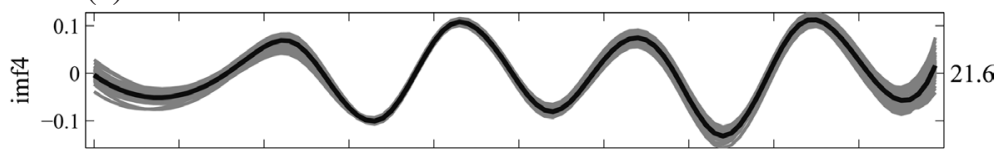

(f)

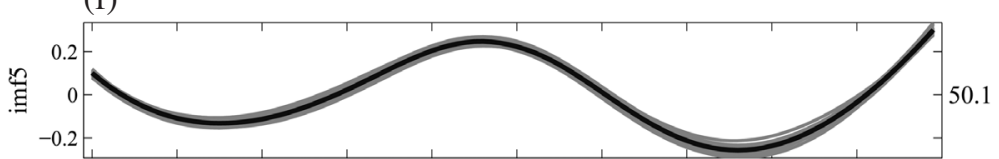

(g)

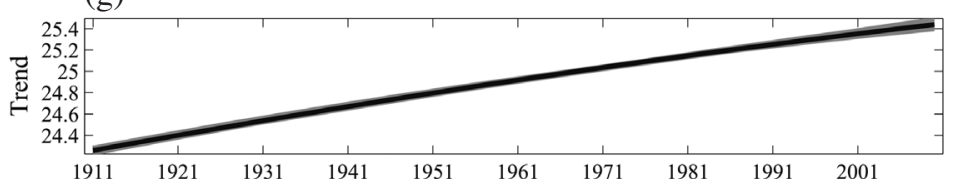

Fig. 2. IMFs of the one hundred year 1911 - 2010 annual mean temperature data at Hengchun station obtained using EEMD with the parameters (S, $\mathrm{N}, \sigma, \mathrm{I})$ as $(10,100,0.1,50)$. See the text for an explanation of the parameters. The raw data is shown in (a), IMFs $1-5$ are in (b) - (f), the secular trend derived by removing all IMFs is in $(\mathrm{g})$.

Table 1 . The statistically significant multidecadal modes of Taiwan temperature extracted by the EEMD method. The EEMD analysis is applied to the 100-year $(1911$ - 2010) time series of the annual and seasonal mean temperatures at 6 long-history stations in Taiwan. The station names are given in the first column. The second column is the annual mean temperature analysis result. The third to fourteenth columns are the seasonal mean temperature results. The content boxes show the IMFs that pass the $95 \%$ confidence level test. The number before the parenthesis is the IMF mode number. The number in the parenthesis is the corresponding IMF period in the unit of years.

\begin{tabular}{|c|c|c|c|c|c|c|c|c|c|c|c|c|c|}
\hline \multirow{2}{*}{ Station } & \multirow{2}{*}{ Annual } & \multicolumn{12}{|c|}{ Season } \\
\hline & & NDJ & DJF & JFM & FMA & MAM & AMJ & MJJ & JJA & JAS & ASO & SON & OND \\
\hline Taipei & & IMF5(50) & & & IMF5(81) & & & & & & & IMF5(91) & \\
\hline Taichung & IMF5(94) & IMF5(92) & & & & & IMF5(91) & & & IMF5(94) & IMF5(92) & IMF5(67) & IMF5(98) \\
\hline Tainan & IMF5(86) & IMF5(92) & & IMF5(94) & & & & & IMF5(96) & IMF5(82) & & IMF5(86) & IMF5(97) \\
\hline Hengchun & IMF5(50) & IMF5(91) & IMF5(91) & IMF5(92) & IMF5(86) & IMF5(95) & & IMF5(93) & & IMF5(50) & & & \\
\hline Taitung & IMF4(43) & IMF5(85) & & & & & IMF5(85) & & IMF5(83) & & & & \\
\hline Hualien & & IMF5(67) & IMF5(97) & & & & IMF5(95) & & IMF5(91) & & & & \\
\hline
\end{tabular}


(a)

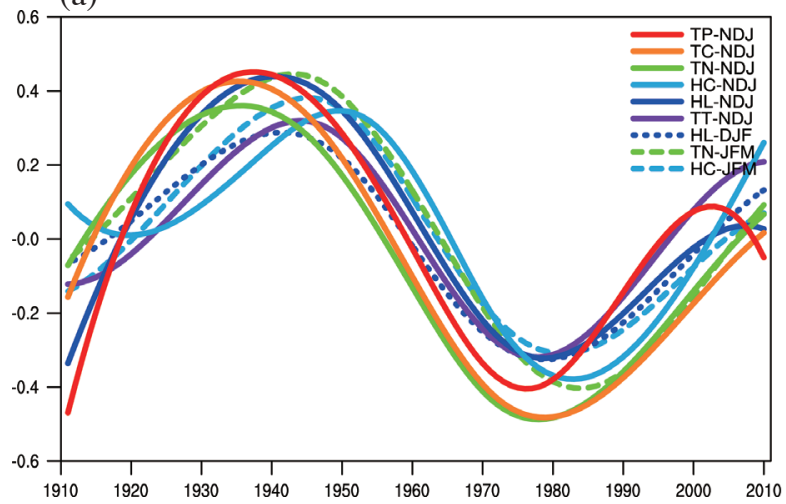

(b)

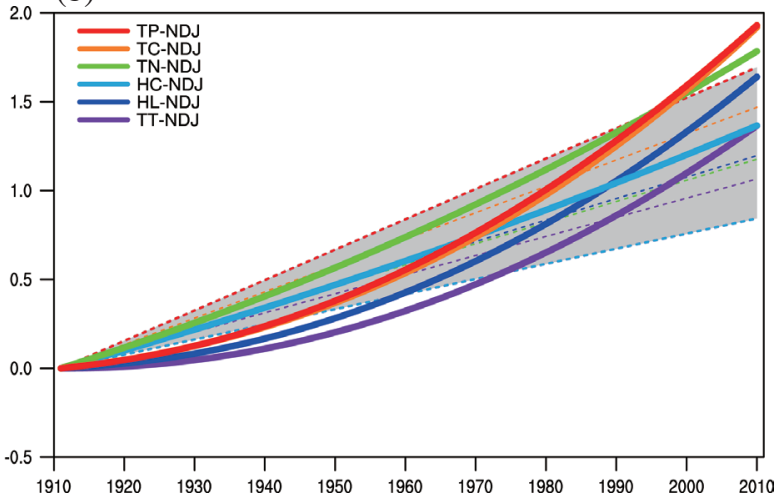

Fig. 3. The time series of (a) the statistically significant (confidence level 95\%) multidecadal (period $>40$ years) IMFs during the winter seasons of NDJ, DJF, and JFM; (b) the linearly regressed (in gray) and secular trend derived from EEMD (in color) of the NDJ temperatures at 6 stations.

influenced by the global climate change. In this session, we will discuss the robustness of the multidecadal variability of the Taiwan winter temperature and how it links to the major global climate variation modes.

\subsection{Teleconnection Pattern of Taiwan Temperature and Global SST Variability}

The Taiwan temperature and global SST correlation in the NDJ season presented in Fig. 4 shows the teleconnection pattern between Taiwan and the globe. Here the Taiwan temperature is the average of the 6 station data. Figure $4 \mathrm{a}$ shows the highest correlation appears over the marginal seas of South and East Asia. Over low-latitude eastern Pacific and extra-tropical western Atlantic also sees high positive correlation. High negative correlation appears over the Coral Sea to the northeast of Australia and high-latitude South Pacific Ocean to the south of Australia and New Zealand, and the South Atlantic Ocean. The correlation pattern changes dramatically when the Taiwan temperature and global SST data were subjected to an 11year running smooth before calculating the low-frequency correlation map (Fig. 4b). The 11-year running smooth suppressed fluctuations with periods shorter than a decade such as ENSO. A distinct difference between Figs. 4a and $b$ is that after filtering the highest correlation is not over the marginal seas of South and East Asia, but over the Atlantic and South Pacific. The western North Pacific $\left(25-30^{\circ} \mathrm{N}\right.$, $150-180^{\circ} \mathrm{E}$ ) and the boundary seas around the Philippines also see high positive correlation. High negative correlation appears over the eastern equatorial Pacific slightly to the north of the Niño 3.4 index $\left(5^{\circ} \mathrm{N}-5^{\circ} \mathrm{S}, 170-120^{\circ} \mathrm{W}\right)$ and a large area over the Southern Hemisphere Tasmania Sea and South Pacific Ocean. Negative correlation also appears over high-latitude South Atlantic. For the regions with similar correlation patterns in the total (Fig. 4a) and low-frequency (Fig. 4b) correlation maps where the decadal-scale varia- tion is dominant over the variations in other time scales particularly the interannual variation. Notably in the Northern Hemisphere the North Pacific region around $30^{\circ} \mathrm{N}$, north Indian Ocean, the marginal seas of north Europe, and in the Southern Hemisphere the Atlantic Niño region, the northwest-southeast oriented slant area over the central South Pacific centered at the box of $\left(10-20^{\circ} \mathrm{S}, 180-140^{\circ} \mathrm{W}\right)$, and the Southern Hemispheric oceans to the south of Australian and New Zealand, the coastal ocean to the west of Chile and high-latitude South Atlantic Ocean are the regions where the multidecadal variability is dominant.

It is worth noting that Fig. 4b shows a negative correlation over the Bohai and Yellow Seas, which is a distinct contrast to Fig. 4a. The out-of-phase pattern along the western boundary of the North Pacific will be discussed in later part of the paper.

\subsection{Global SST Multidecadal Variability and Taiwan Temperature}

In order to interpret Fig. 4b, we need to analyze the major global SST variation modes in terms of the empirical orthogonal function (EOF) analysis (Fig. 5). The linear trends of the time series are removed at each grid point before performing the EOF analysis. The first mode explains $23 \%$ of the total variance, while the second and third modes explain 6.2 and $5.1 \%$ of the total variance, respectively. The correlation coefficient table (Table 2) shows as high as 0.98 correlation between the first mode (EOF-1) and the IPO mode (Henley et al. 2015). The correlation between EOF-1 and the ENSO index Niño 3.4 is also as high as 0.97 . However, its correlation with Taiwan NDJ temperature (11-year smoothed) is near zero. Large similarity can be found in Figs. 4a and 5a. EOF-1 describes shorter-than-a-decade variability in the global SST represented by ENSO over the tropical Pacific and IPO over the entire Pacific that is influential to the Taiwan temperature variability in the same time scale. 
Table 2 shows high correlation between the Taiwan NDJ temperature and the second and third EOF modes. EOF-2 shows high correlation only with AMO, while EOF3 shows high correlations with both AMO and PDO. The correlation between the Taiwan NDJ temperature and EOF3 is not as high as with EOF-2, but it is significant at the 99.9\% confidence level. In fact, IMF5 of the Taiwan winter temperature (Fig. 3a) shows remarkable coherence with the AMO index presented at https://climatedataguide.ucar.edu/ climate-data/atlantic-multi-decadal-oscillation-amo.

The high correlations between the Taiwan NDJ temperature and the leading modes provide strong evidence to interpret the multidecadal variations in Taiwan temperature as part of the major multidecadal global SST variability modes.

The relation between the global SST variability and Taiwan temperature can be further understood using the correlation map between the Taiwan NDJ temperature and the reconstructed global SST from EOF-2 and EOF-3 (Fig. 6). It is interesting to see a narrow high correlation front surrounds a rectangular box low correlation area with a rough boundary at longitudes from $120^{\circ} \mathrm{E}-160^{\circ} \mathrm{W}$ and latitudes from $30-50^{\circ} \mathrm{N}$. A high positive correlation front around $25^{\circ} \mathrm{N}$ crosses over southeast Taiwan. The high correlation and its front over the Pacific Ocean highlight Taiwan's unique geo- graphical location that makes the temperature record special in reflecting the multidecadal variability represented by EOF-2 and EOF-3. As a result, the Taiwan NDJ temperature shows in-phase relationship with the SST variations in the areas of extra-tropical and tropical western North Pacific and the extra-tropical central South Pacific, and out-of-phase relationship with the equatorial central Pacific. Other than the Pacific Ocean, high positive correlations also appear over the North Atlantic, Indian Ocean and Arctic Oceans and the marginal seas to the north and south of Australia and to the southeast of South America. The mid-latitude oceans in the Southern Hemisphere see high negative correlation.

The associated large-scale features to the concurrent multidecadal SST and Taiwan NJD temperature variations are illustrated in the regression maps in Figs. $7 \mathrm{a}$ and $\mathrm{b}$. The regression is made onto a reference time series of the EOF-2 and EOF-3 reconstructed SST averaged near Taiwan (127 $\left.138^{\circ} \mathrm{E}, 23-28^{\circ} \mathrm{N}\right)$. The time series of large-scale variables such as the wind fields at 925- and 200-hPa, SLP and the geopotential height at 500-hPa are detrended and smoothed by 11-year moving average before carrying out the regression. Figure 7a shows an interesting meridional pattern in the regressed $500-\mathrm{hPa}$ geopotential height with positive phase in the tropics and Arctic, and negative phase in the
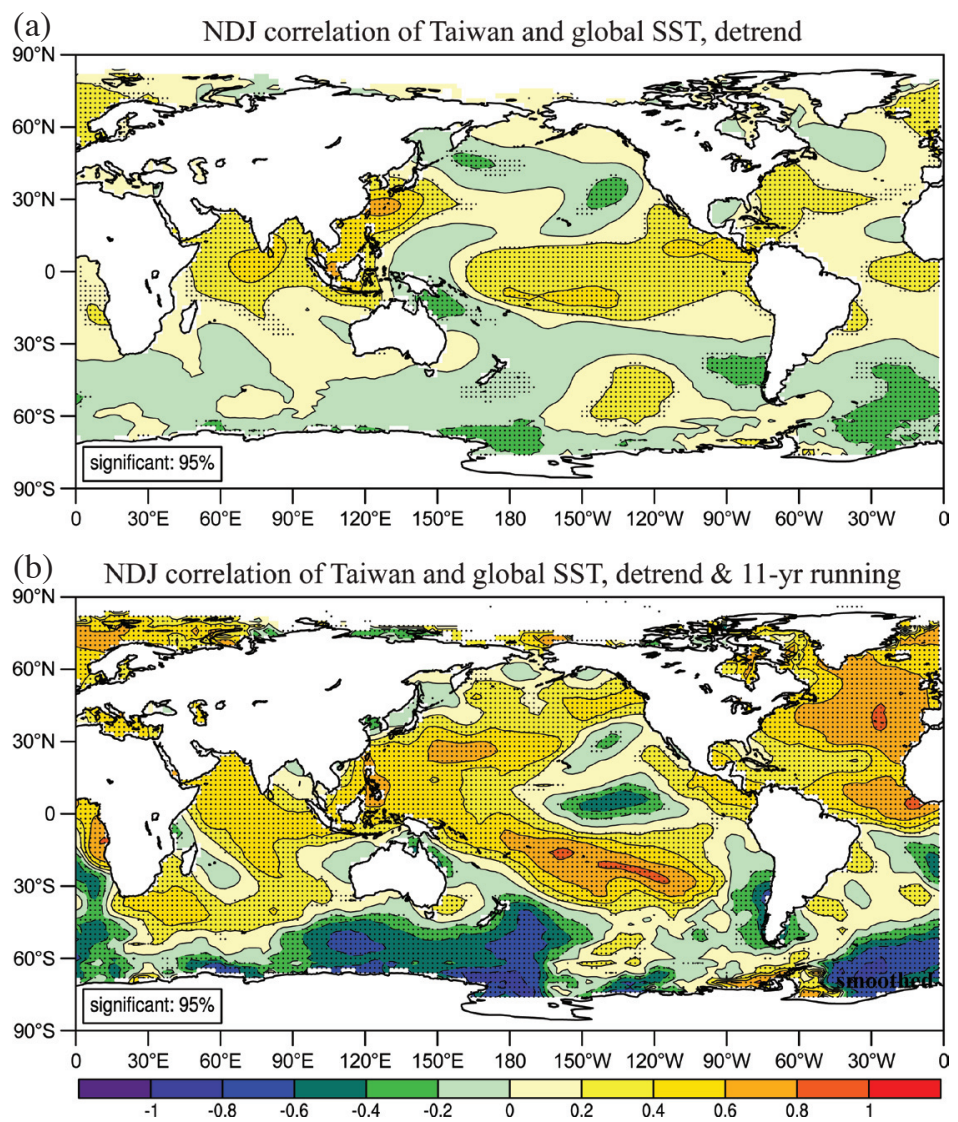

Fig. 4. Correlation between SST and Taiwan NDJ temperature averaged over 6 stations for 1911 - 2010, (a) without and (b) with 11-year running smoothed. Correlation significant at the $95 \%$ confidence level is indicated by stippling. 

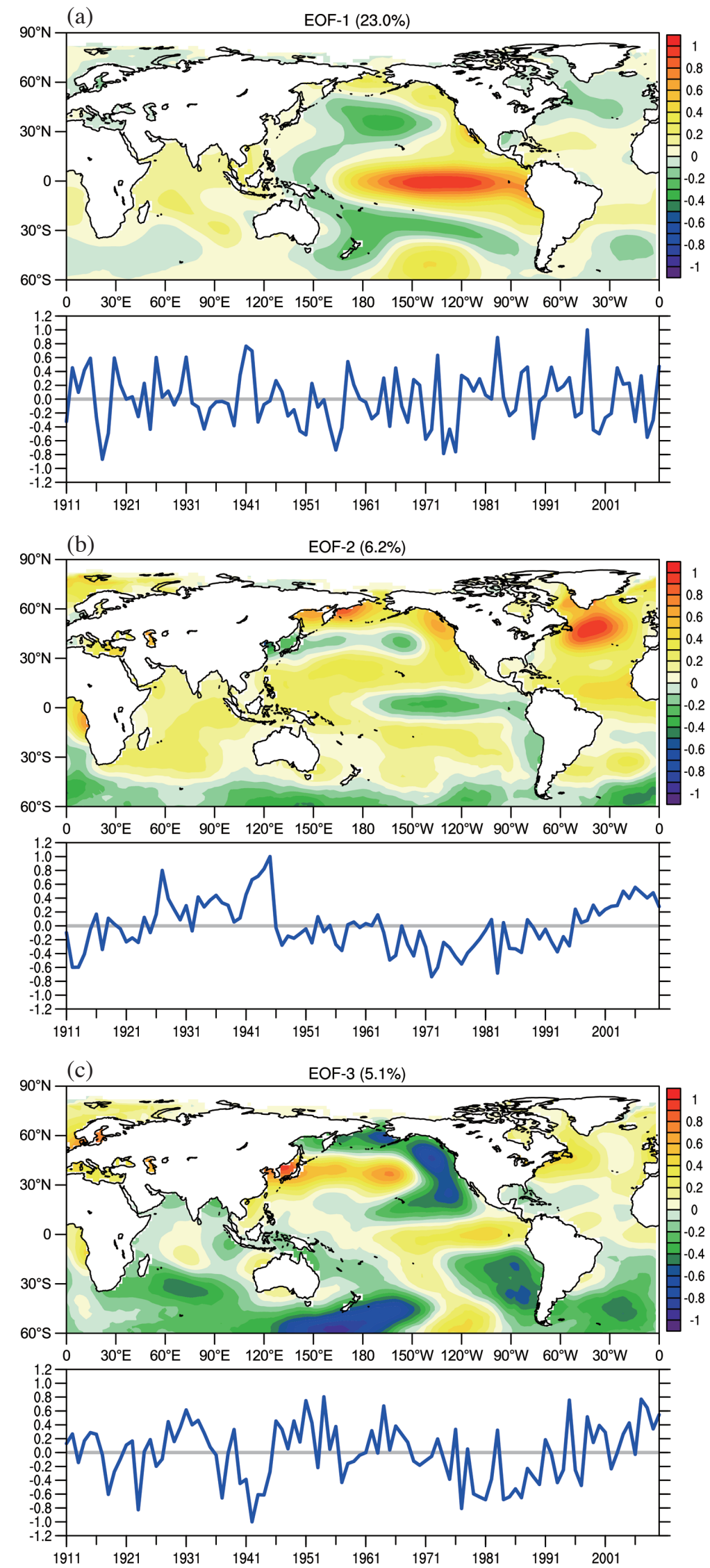

Fig. 5. Spatial patterns ad temporal behavior of the EOFs of the global SST in NDJ from 1911 - 2010 of which the linear trend of the time series at each grid is removed. (a) EOF-1, (b) EOF-2, (c) EOF-3. 
Table 2. Correlation between three major modes of global SST and Taiwan NDJ temperature, ENSO index, IPO, PDO, and AMO indices. The values that are significant at the $99.9 \%$ confidence level are marked by $* * *$.

\begin{tabular}{cccccc}
\hline Global SST Principal Comp. & TWN station temp. (NDJ) & NINO3.4 & IPO & PDO & AMO \\
\hline EOF-1 & 0.04 & $0.97 * * *$ & $0.98^{* * *}$ & $0.54^{* * *}$ & 0.03 \\
EOF-2 & $0.55^{* * *}$ & 0.07 & 0.11 & 0.14 & $0.72^{* * *}$ \\
EOF-3 & $0.42^{* * *}$ & 0.14 & 0.02 & $0.46^{* * * *}$ & $0.47 * * *$ \\
\hline
\end{tabular}

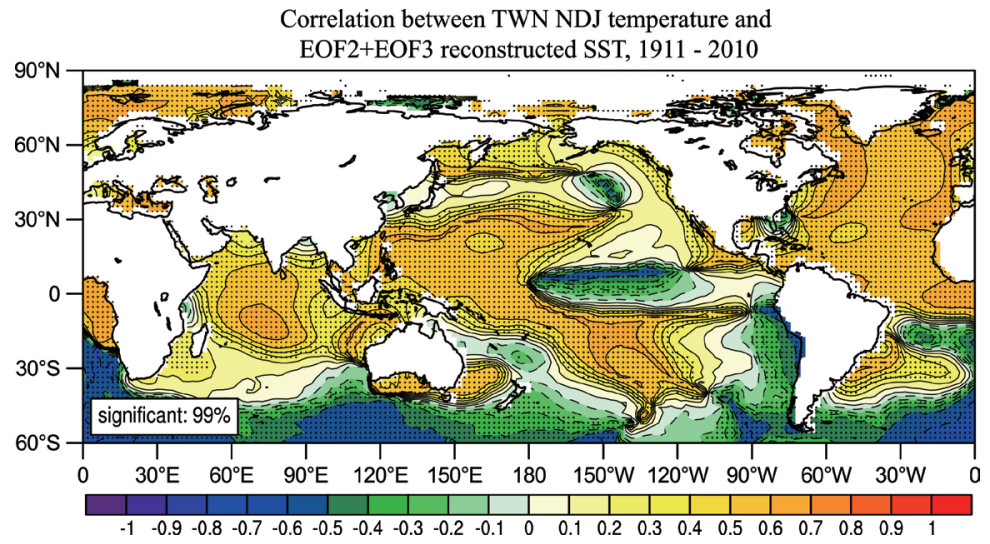

Fig. 6. Correlation between the reconstructed SST from EOF-2 and EOF-3 of the global SST EOF analysis and Taiwan NDJ temperature averaged over 6 stations for 1911 - 2010, with the detrend preprocess and 11-year running smoothed. Correlation significant at the $99 \%$ confidence level is indicated by stippling.

(a)

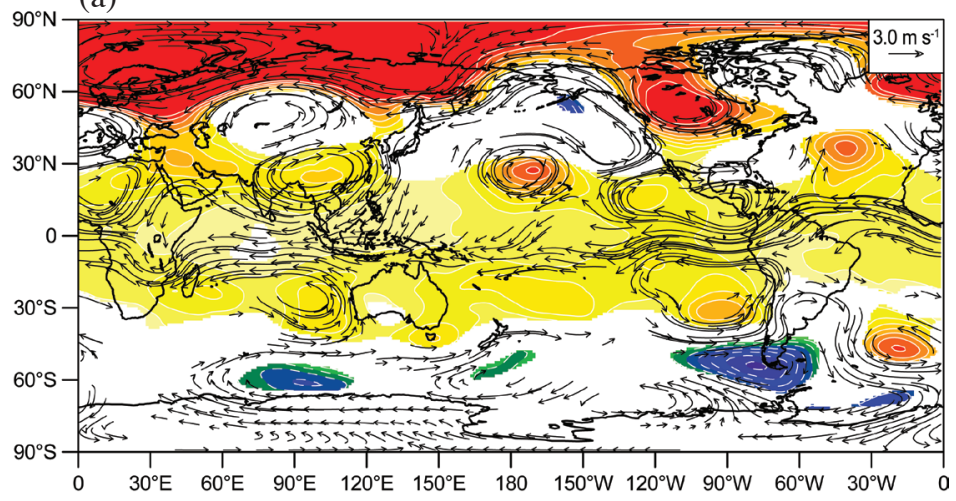

(b)

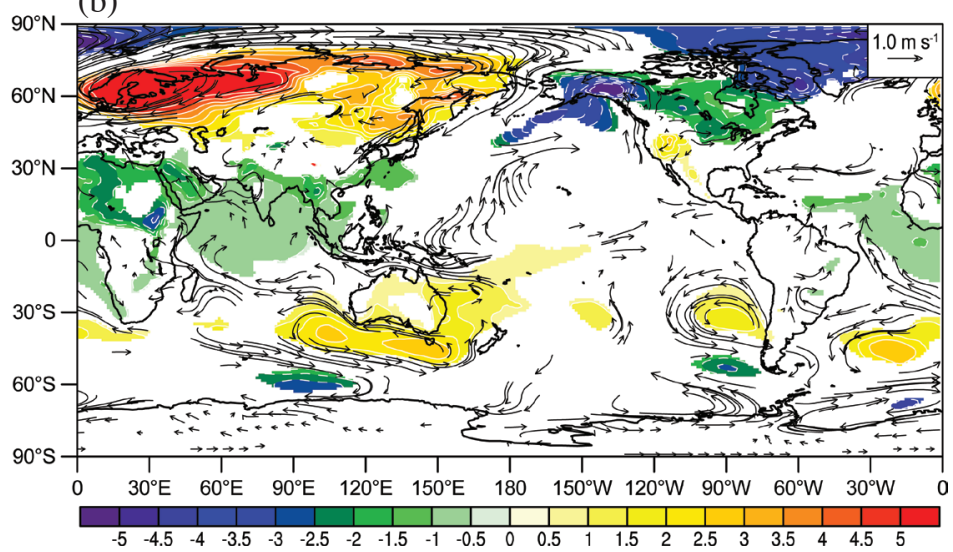

Fig. 7. Regression of the detrend and 11-year running smoothed (a) 200-hPa winds and 500-hPa geopotential height and (b) 925-hPa winds and SLP onto the reconstructed SST from EOF-2 and EOF-3 averaged near Taiwan $\left(127-138^{\circ} \mathrm{E}, 23-28^{\circ} \mathrm{N}\right)$ for the period $1911-2010$. Only regressions significant at the $99 \%$ confidence level of a t-test are plotted. 
mid-latitudes on both North and South Hemispheres. When focusing on the $30^{\circ} \mathrm{N}$ latitude we see a zonal wavenumber 5 wave pattern with five outstanding anticyclonic eddies over northwest Africa, East Asia, and extra-tropical North Pacific, tropical East Pacific, extra-tropical Atlantic Oceans. The anticyclones over East Asia and the associated easterly anomalies around the equator are particularly relevant to the present study. The anomalous anticyclone implies weaker subtropical jet stream along the southern rim of the Tibetan Plateau, which often results in a more stable weather condition in Taiwan and less frequent cold air intrusion from Siberia to Southeast Asia. Interestingly, the $120-60^{\circ} \mathrm{W}$ longitudinal band sees a similar meridional structure as the pattern over the $60-120^{\circ} \mathrm{E}$ band. The implication of such similarity is not yet clear to the authors.

Figure $7 \mathrm{~b}$ shows positive SLP over the northern Eurasian continent and Australia and the Southern Ocean, and negative SLP over Africa, the Indian Ocean and South Asia. The regressed low-level winds show easterly phase over Indonesia maritime continent and southerly phase over the western North Pacific. It is of particular importance to note that the regressed wind pattern is consistent with the Atlantic-induced pan-tropical circulation proposed in McGregor et al. (2014), Li et al. (2015), and Kucharski et al. (2016). The proposed mechanism emphasizes the out-of-phase relationship between the SST anomalies over the equatorial central Pacific SST and that over the western Pacific and Indian Ocean, which forms an atmosphere-ocean coupled environment encouraging the positive feedback process that enhances the PDO type of SST anomalies forced by AMO. Such an out-of-phase SST pattern is clearly shown in Fig. 6. The remarkable consistency between the regression maps onto the near Taiwan reconstructed SST (Fig. 7) and the correlation map with Taiwan station data (Fig. 6) suggests the robustness of the multidecadal mode of Taiwan NDJ temperature. In other words, the IMF5 obtained from the EEMD decomposition is a robust climate signal rooted in the combined influence of the EOF-2 and EOF-3 of global SST variability. The EOF-2 over the Atlantic resembles the AMO. The EOF-3 over the North Pacific resembles the PDO and over the Atlantic resembles the part of AMO that is correlated with PDO.

\subsection{Possible Influence of the Decadal Mode NPGO}

The findings in this study are consistent with the published results about the multidecadal variability over the $\mathrm{Pa}$ cific, Atlantic and Indian oceans (Messié and Chavez 2011, hereafter referred to as MC11; Deser et al. 2010a; Furtado et al. 2012; McGregor et al. 2014; Li et al. 2015; Kucharski et al. 2016). MC11 carried out an EOF analysis of a centurylong global SST to reveal the temporal and spatial structures of the major climate variability modes that include the ENSO, AMO, PDO, NPGO, El Niño Modoki (CP-EN), and the Atlantic El Niño (AT-EN). Different modes exhibit a different principal frequency in the fluctuations. The decadal changes in the North Pacific can be described by NPGO (Di Lorenzo et al. 2010; Furtado et al. 2012) and the combination of ENSO and PDO. The spatial pattern of the SST anomalies associated with the NPGO mode (Fig. 10 in $\mathrm{MC11}$ ) shows a clear contrast between the positive and negative phases in the west boundary area of the tropical and subtropical North Pacific and the Asian marginal seas. The SSTs of the South China Sea, the Philippine Sea and the south boundary of the East China Sea near Taiwan tend to be positive (negative) when the NPGO is in its positive (negative) phase. On the other hand, the SST pattern of the combined ENSO and PDO (Fig. 10 in MC11) shows that the East China Sea SST tends to be positive (negative) when the $\mathrm{PDO}$ is in its negative (positive) phase.

Although the Taiwan NDJ temperature is highly correlated with AMO (Table 2), the transition period (1950s to mid-1970s), during which the Taiwan climate changed from warm to cold occurred when the NPGO (the Mode 4 in MC11) was in a strong negative phase. During the past decade when the Taiwan climate changed from cold to warm, the NPGO was found to be strong positive and the PDO was in its' strong negative phases. The combined NPGO and PDO effect implies a greatly enhanced transport in the Pacific subtropical gyres (Figs. 7b and 10 in MC11), which can enhance the SST warming rate in the western boundary of the tropical and subtropical North Pacific and Asian marginal seas.

The possible influence of NPGO is speculative. More thorough analysis is beyond the scope of this study and will be published in a separate paper.

\section{CONCLUSION}

We used the EEMD method to decompose the 100-year (1910 - 2010) Taiwan temperature data and investigated the influence of the multidecadal modes on the centennial trend and their seasonal dependence. The statistically significant multidecadal modes appear mainly in winter months. A warm regime is identified from 1931 - 1950 and a cold regime is from 1971 - 1990. The period from 1951 - 1970 is a transition period during which the local climate changed from a warm to cold regime. In the recent two decades since 1991 Taiwan climate saw a transition from a cold to warm regime. It is likely that the peak of the current warm regime has not yet passed.

We presented the robustness of the multidecadal variability in Taiwan temperature. The multidecadal variability has its root in the major global SST variability modes. Taiwan's geographic location is important because it links the global modes to local climate. The regional climate over the western subtropical boundary of the Pacific is strongly modulated by the East Asian winter and summer monsoons. 
However, the sub-decadal and multidecadal variability scales are influenced by different factors. The multidecadal scale variability is influenced mainly by the AMO and PDO through the Atlantic-induced climate changes in the Pacific and Indian Ocean. The sub-decadal scale variability is influenced mainly by the ENSO and PDO.

The ST obtained from EEMD analysis shows a warming rate that surpasses the linear trend after 1991. Because the multidecadal mode shows the recent two decades in a cold to warm transition period, the sharp warming in the ST after 1991 suggests a strong cooling effect during recent decades caused by the sub-decadal variations, while the possibility of anthropogenic influence cannot be ruled out. Further studies are needed to quantify the warming rate percentage contributed by the variations in different timescales.

Acknowledgements The work was jointly supported by the Central Weather Bureau and National Science Council (NSC 99-2625-M-003-001-MY3 and NSC 99-2625-M-492-001) of Taiwan. The IPO, PDO, AMO index data are obtained from NOAA's Earth System Research Laboratory website (http://www.esrl.noaa.gov/psd/data/climateindices/).

\section{REFERENCES}

DelSole, T., M. K. Tippett, and J. Shukla, 2011: A significant component of unforced multidecadal variability in the recent acceleration of global warming. J. Climate, 24, 909-926, doi: 10.1175/2010JCLI3659.1. [Link]

Deser, C., M. A. Alexander, S. P. Xie, and A. S. Phillips, 2010a: Sea surface temperature variability: Patterns and mechanisms. Annu. Rev. Mar. Sci., 2, 115-143, doi: 10.1146/annurev-marine-120408-151453. [Link]

Deser, C., A. S. Phillips, and M. A. Alexander, 2010b: Twentieth century tropical sea surface temperature trends revisited. Geophys. Res. Lett., 37, L10701, doi: 10.1029/2010GL043321. [Link]

Di Lorenzo, E., K. M. Cobb, J. C. Furtado, N. Schneider, B. T. Anderson, A. Bracco, M. A. Alexander, and D. J. Vimont, 2010: Central Pacific El Niño and decadal climate change in the North Pacific Ocean. Nat. Geosci., 3, 762-765, doi: 10.1038/Ngeo984. [Link]

Furtado, J. C., E. Di Lorenzo, B. T. Anderson, and N. Schneider, 2012: Linkages between the North Pacific Oscillation and central tropical Pacific SSTs at low frequencies. Climate Dyn., 39, 2833-2846, doi: 10.1007/ s00382-011-1245-4. [Link]

Guan, B. and S. Nigam, 2008: Pacific sea surface temperatures in the twentieth century: An evolution-centric analysis of variability and trend. J. Climate, 21, 27902809, doi: 10.1175/2007JCLI2076.1. [Link]

Guan, B. and S. Nigam, 2009: Analysis of Atlantic SST variability factoring interbasin links and the secular trend: Clarified structure of the Atlantic multi- decadal oscillation. J. Climate, 22, 4228-4240, doi: 10.1175/2009JCLI2921.1. [Link]

Henley, B. J., J. Gergis, D. J. Karoly, S. Power, J. Kennedy, and C. K. Folland, 2015: A Tripole Index for the Interdecadal Pacific Oscillation. Climate Dyn., 45, 3077 3090 doi: 10.1007/s00382-015-2525-1. [Link]

Huang, N. E., Z. Shen, S. R. Long, M. C. Wu, H. H. Shih, Q. Zheng, N. C. Yen, C. C. Tung, and H. H. Liu, 1998: The empirical mode decomposition and the Hilbert spectrum for nonlinear and non-stationary time series analysis. Proc. Math. Phys. Eng. Sci., 454, 903-995, doi: 10.1098/rspa.1998.0193. [Link]

Huang, N. E., Z. Shen, and S. R. Long, 1999: A new view of nonlinear water waves: The Hilbert spectrum. Annu. Rev. Fluid Mech., 31, 417-457, doi: 10.1146/annurev. fluid.31.1.417. [Link]

Kucharski, F., F. Ikram, F. Molteni, R. Farneti, I. S. Kang, H. H. No, M. P. King, G. Giuliani, and K. Mogensen, 2016: Atlantic forcing of Pacific decadal variability. Climate Dyn., 46, 2337-2351, doi: 10.1007/s00382015-2705-z. [Link]

Li, X., S. P. Xie, S. T. Gille, and C. Yoo, 2015: Atlanticinduced pan-tropical climate change over the past three decades. Nat. Clim. Change, 6, 275-279, doi: 10.1038/ NCLIMATE2840. [Link]

McGregor, S., A. Timmermann, M. F. Stuecker, M. H. England, M. Merrifield, F. F. Jin, and Y. Chikamoto, 2014: Recent Walker circulation strengthening and Pacific cooling amplified by Atlantic warming. Nat. Clim. Change, 4, 888-892, doi: 10.1038/NCLIMATE2330. [Link]

Messié, M. and F. Chavez, 2011: Global modes of sea surface temperature variability in relation to regional climate indices. J. Climate, 24, 4314-4331, doi: 10.1175/2011JCLI3941.1. [Link]

Semenov, V. A., M. Latif, D. Dommenget, N. S. Keenlyside, A. Strehz, T. Martin, and W. Park, 2010: The impact of North Atlantic-Arctic multidecadal variability on Northern Hemisphere surface air temperature. J. Climate, $\mathbf{2 3}$, 5668-5677, doi: 10.1175/2010JCLI3347.1. [Link]

Smith, T. M., R. W. Reynolds, T. C. Peterson, and J. Lawrimore, 2008: Improvements to NOAA's historical merged land-ocean surface temperature analysis (1880-2006). J. Climate, 21, 2283-2296, doi: 10.1175/2007JCLI2100.1. [Link]

Solomon, A. and M. Newman, 2012: Reconciling disparate twentieth-century Indo-Pacific ocean temperature trends in the instrumental record. Nat. Clim. Change, 2, 691-699, doi: 10.1038/nclimate1591. [Link]

Wu, Z. and N. E. Huang, 2005: Statistical significance test of intrinsic mode functions. In: Huang, N. E. and S. S. P. Shen (Eds.), Hilbert-Huang Transform and Its Applications, World Scientific Publishing, 107-127, doi: 10.1142/9789812703347_0005. [Link] 
Wu, Z. and N. E. Huang, 2009: Ensemble empirical mode decomposition: A noise-assisted data analysis method. Adv. Adapt. Data Anal., 1, 1-41, doi: 10.1142/ S1793536909000047. [Link]

Wu, Z., N. E. Huang, S. R. Long, and C. K. Peng, 2007: On the trend, detrending, and variability of nonlinear and nonstationary time series. PNAS, 104, 14889-14894, doi: 10.1073/pnas.0701020104. [Link]

Wu, Z., N. E. Huang, J. M. Wallace, B. V. Smoliak, and X. Chen, 2011: On the time-varying trend in global-mean surface temperature. Climate Dyn., 37, 759-773, doi: 10.1007/s00382-011-1128-8. [Link] 